\title{
Surgical ligation level of the bronchial artery influences tissue oxygen saturation of the bronchus and the incidence of postoperative bronchofistula after pulmonary lobectomy
}

\author{
Marino Yamamoto $^{1 \#}$, Takashi Anayama ${ }^{1 \#} \wedge$, Hironobu Okada ${ }^{1} \wedge$, Ryohei Miyazaki $^{1} \wedge$, Kazumasa Orihashi $^{2} \wedge$ \\ ${ }^{1}$ Department of Thoracic Surgery, Kochi Medical School, Kochi University, Kochi, Japan; ${ }^{2}$ Department of Surgery II, Kochi Medical School, Kochi \\ University, Kochi, Japan
}

\#These authors contributed equally to this work.

Correspondence to: Takashi Anayama. Kohasu Oko Nankoku Kochi 783-8505, Japan. Email: anayamat@kochi-u.ac.jp.

\begin{abstract}
Background: Lobectomy, or the removal of a lobe of the lung, is the most commonly performed lung cancer surgery. One of the most severe postoperative complications is a bronchial stump fistula, which often occurs following a right lower lobectomy. During lymph node dissection, the bronchial arteries, which supply blood to the bronchus, are cut. Subsequently, reduced blood supply to the bronchus may result in bronchofistula. We investigated the relationship between the level of the surgical ligation of the bronchial arteries and the decrease in blood flow at the bronchial stump during a right lower lobectomy. This study aimed to clarify the relationship between the anatomical amputation level of the bronchial artery and the decrease in tissue oxygen saturation at the bronchial stump, allowing us to identify a surgical procedure that reduces the risk of a bronchopleural fistula following pulmonary lobectomy and an appropriate bronchial artery amputation site that could be used in future lobectomies.
\end{abstract}

Methods: We developed a new system (micro-tissue oxygen saturation) that enabled the semi-quantification of the oxygen saturation of thin tissues in pinpoint during video-assisted thoracic surgery. Changes in the blood flow at the bronchial stump were examined during lymph node dissection and bronchial artery amputation using a biological pig lobectomy model.

Results: The regional oxygen saturation level at the bronchial wall was $95.5 \% \pm 1.0 \%$ in normal conditions. A gradual decrease in regional oxygen saturation was observed, as the cutting point of the bronchial artery was moved higher. When the bronchial artery coursing into the middle lobe bronchus was preserved, the blood flow in the bronchus was preserved at $82.8 \% \pm 1.3 \%$. When the branches of the bronchial arteries running both inside and outside of the intermediate bronchial trunk were cut at high positions, regional oxygen saturation level decreased to $55.7 \% \pm 1.2 \%$.

Conclusions: The preservation of at least one bronchial artery at the level of the middle lobe bronchus minimizes the reduction of tissue oxygen saturation at the lower lobe bronchial stump. The ligation of bronchial arteries at a higher position results in desaturation $<60 \%$, which may increase the risk of bronchial stump fistula.

Keywords: Pulmonary lobectomy; bronchial artery; regional saturation of oxygen; near-infrared spectroscopy; postoperative bronchofistula

Submitted Sep 13, 2020. Accepted for publication Mar 07, 2021.

doi: $10.21037 /$ qims-20-1057

View this article at: http://dx.doi.org/10.21037/qims-20-1057

^ORCID: Marino Yamamoto, 0000-0001-7877-6229; Takashi Anayama, 0000-0002-3989-6268; Ryohei Miyazaki, 0000-0002-4043-049X; Hironobu Okada, 0000-0001-9355-7972; Kazumasa Orihashi, 0000-0003-2606-8436. 


\section{Introduction}

Postoperative leakage of a surgical anastomosis, such as those in the intestinal tract or bronchus, is a major postoperative complication $(1,2)$. Suture failure occurs when local blood flow in the affected tissue is reduced, which causes hypoxia in the sutured tissue and delays the healing process. Therefore, preserving locally distributed blood vessels to maintain blood flow to sutured tissue is crucial.

Bronchopleural fistula (BPF) is one of the most serious complications of lobectomy (2). The incidence of a BPF following a lobectomy is $0.5 \%$, and the mortality rate of patients with a BPF is $27 \%(3-5)$. BPFs most often occur following right lower lobectomies and have a postoperative incidence rate of $1.1-1.7 \%$ (6). BPF is also common after pneumonectomy, and the incidence is higher (4.5\%) than after lobectomy (5). Decreased local blood flow is generally the main cause of delayed healing or suture failure. BPF may be also caused by decreased blood flow through bronchial arteries at the bronchial stump.

Bronchial arteries branch right and left from the descending aorta and the intercostal arteries and feed the lungs and bronchi (7). From the right bronchial artery, multiple branches run into the periphery of the lower right lobe. One artery descends from the carina inside the bronchi. Another artery branches to the upper right lobe and then down to the middle trunk, exits the middle lobe bronchus, and finally courses into the lower right lobe bronchus (8-10).

The standard procedure for the curative resection of lung cancer in the right lower lobe is a right lower lobectomy and mediastinal lymph node dissection (11). In this procedure, the hilar lymphatic tissue that covers the bronchus is excised to remove the metastatic lymph nodes. For the lobectomy of the lower lobe, the lymphatic tissue on both the outside and inside of the inferior trunk of the bronchus is dissected during lymph node dissection, and the peripheral branches of the bronchial arteries are ligated along with the lymph nodes. Ligation of the bronchial arteries in the central part of the lobe results in reduced tissue oxygenation in the peripheral bronchus.

Indocyanine green (ICG) fluorescence has previously been used to evaluate blood flow during surgery. The ICG fluorescence technique evaluates blood flow by visualizing the fluorescence of ICG in the blood, as it is administered systemically from outside of the body. This visualization is possible with a near-infrared camera because the wavelength of the light fluorescence excitation is in the near-infrared region, and there is a high level of tissue permeability. This technique is safe for the human body and is often used to monitor coronary artery bypass blood flow and muscle valve blood flow (12-15). Blood flow in the bronchial arteries can be visualized with ICG fluorescence during thoracic surgery for lung cancer (Figure 1). However, this qualitative evaluation only determines the presence or absence of fluorescence. Quantitation of tissue oxygenation levels is difficult with this modality.

By contrast, the tissue oxygen saturation (TOS)OR regional oxygen saturation $\left(\mathrm{rSO}_{2}\right)$ monitor (Fujita
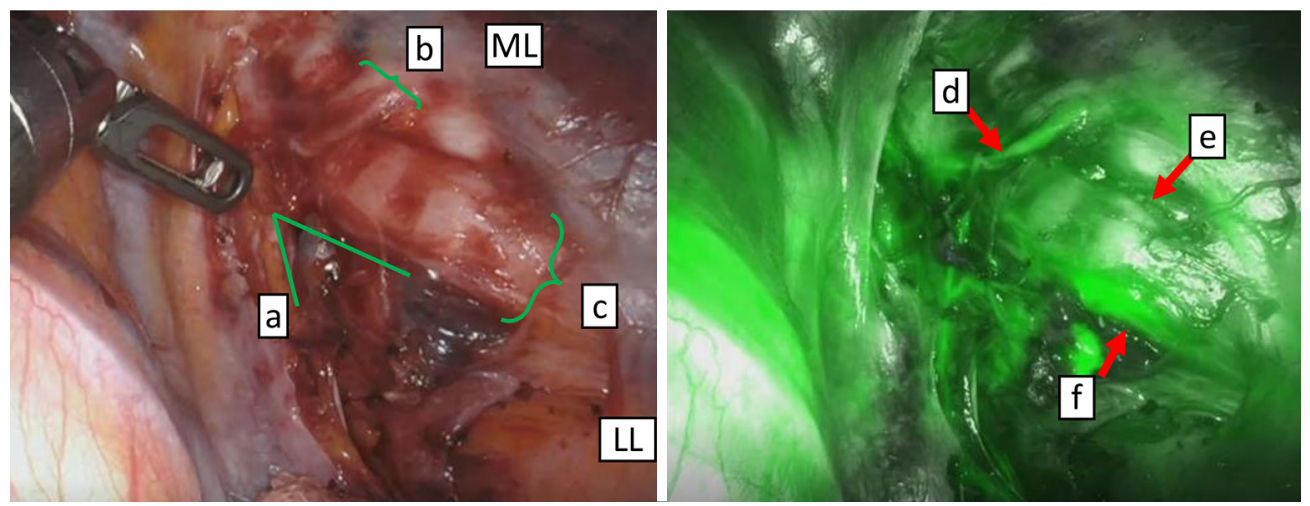

Figure 1 Thoracoscopic image of the tracheal bifurcation observed from the dorsal side of the right thorax. The white light image (on the left) and the infrared fluorescent image (on the right) of right bronchus. The anatomical tracheal bifurcation (a), right middle bronchial trunk (b), and right lower bronchial trunk (c) were visualized by a white light thoracoscope. One of the right bronchial arteries branches into the right middle lobe bronchus (d) and the lower lobe bronchus (e). Another bronchial artery descends the inside of the bronchus to the lower lobe bronchus (f). ML, right middle lobe; LL, right lower lobe. 


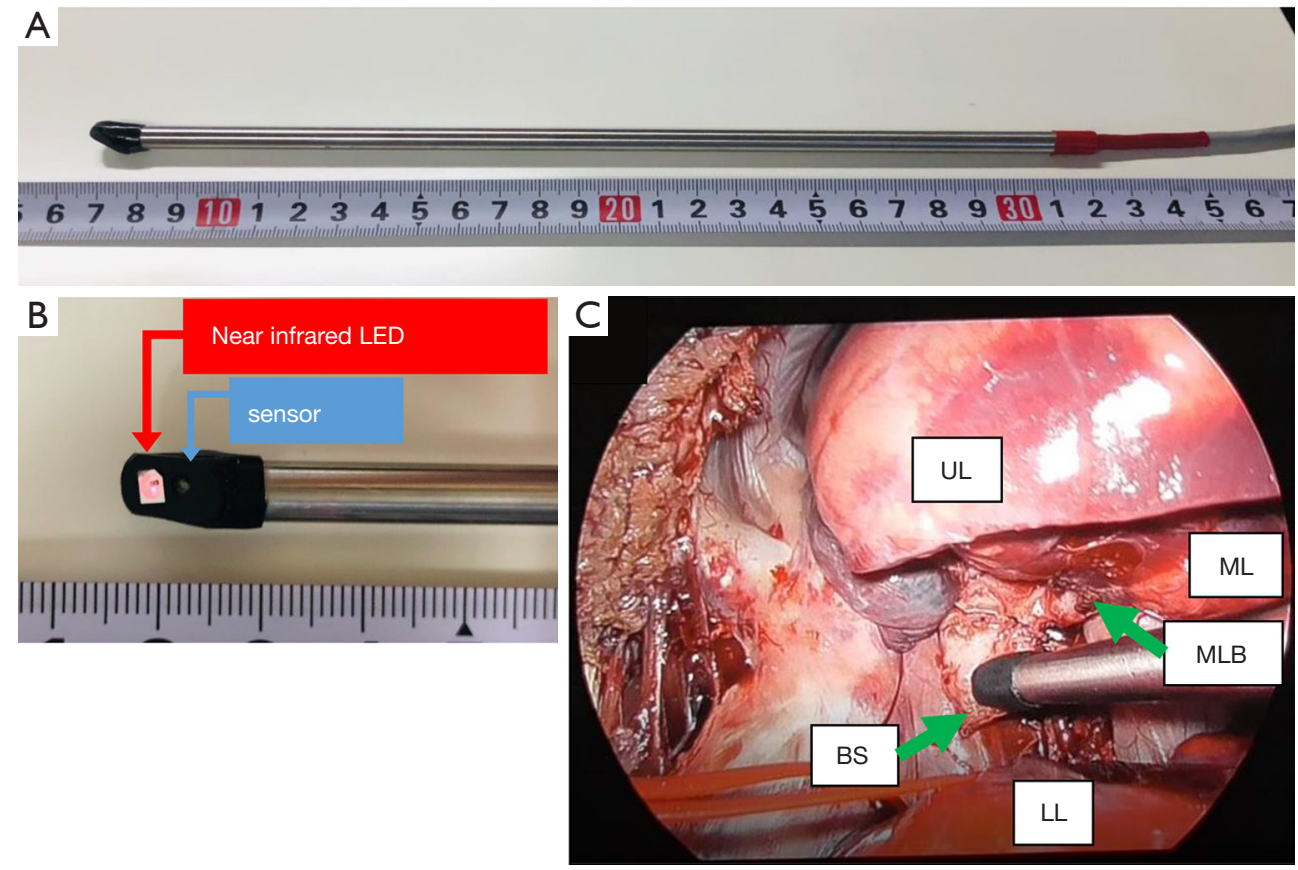

Figure 2 The newly developed micro-TOS sensor and thoracoscopic tissue oxygen saturation measurement. (A) An extremely smallsized tissue oxygen saturation monitor was molded into a rod with a diameter of $8 \mathrm{~mm}$ and a length of $250 \mathrm{~mm}$ to be inserted through the access port during endoscopic surgery. (B) A near-infrared LED and a near-infrared sensor were built on the tip of the rod. (C) When the surrounding area was covered with black resin and brought into close contact with the tissue, tissue oxygen saturation could be measured in a state where local light was shielded. UL, upper lobe of right lung; ML, middle lobe; LL, lower lobe; MLB, middle lobe bronchus; BS, bronchial stump (the location of the cut and stapled inferior trunk).

Medical Instruments, Tokyo, Japan) (16) and the INVOS system (Medtronic, Tokyo, Japan) (17) have been used to quantitatively measure TOS levels using a non-invasive near-infrared spectroscopy technique. In this technique, the near-infrared light that has entered the tissue is absorbed by oxygenated and deoxygenated hemoglobin $(\mathrm{Hb})$. The oxygen saturation can then be measured from the varying $\mathrm{Hb}$ absorption rates because oxygenated and deoxygenated $\mathrm{Hb}$ have different near-infrared light absorption characteristics (18).

The TOS-OR $\mathrm{rSO}_{2}$ monitor and INVOS system can measure oxygen saturation in tissue at depths of $2-3 \mathrm{~cm}$ or more (18). They are frequently used to monitor cerebral blood flow during general anesthesia surgery and evaluate blood flow in pedicled flaps in the field of plastic surgery. While these tools may be used to measure oxygen saturation in the deep parts of thick tissues, they cannot quantify oxygen saturation in thin tissues, such as the bronchus or intestinal tract, with a thickness of $<1 \mathrm{~cm}$.

In this study, we developed a new micro-TOS system that can semi-quantify oxygen saturation in thin tissues. Then, we used a biological pig lobectomy model to investigate the changes in blood flow at the bronchial stump, following lymph node dissection and bronchial artery amputation. Thus, this study aimed to clarify the influence of the level of the surgical ligation of the bronchial arteries on the reduction of TOS at the bronchial stump, allowing us to identify a surgical procedure that reduces the risk of a bronchopleural fistula following a right lower pulmonary lobectomy and the appropriate bronchial artery amputation site that could be used in future lobectomies.

\section{Methods}

\section{Development of the micro-TOS system}

A sensor compatible with the TOS-OR $\mathrm{rSO}_{2}$ monitor (Fujita Medical Instrument) was shaped into a $250-\mathrm{mm}$ rod (Figure 2) for use in a minimally invasive endoscopic surgery. A light source and a sensor were built into the tip of the stainless-steel rod at a $30^{\circ}$ angle. An ultra-small infrared 
light-emitting diode (LED) light source and two types of infrared light sensors were placed at the tip of the rod. The tips of the sensors were covered with black resin for measurement of the intended targets under light shielding. Three wavelengths of light $(770,805$, and $870 \mathrm{~nm})$ were irradiated from the LED light source for measurement. They were received for measurement by a sensor $6 \mathrm{~mm}$ away from the source. By attaching this custom sensor to the bronchial wall, TOS could be measured at a depth of 4 $5 \mathrm{~mm}$ from the surface of the bronchus. The device captured 10 continuous time series data every second. Validation testing of the micro-TOS system was performed using the small intestine of a live porcine, as the organ has a simple anatomical structure and it is easy to surgically control the blood flow. While blood flow through the intestinal serosa was maintained, the $\mathrm{rSO}_{2}$ level was $80.7 \% \pm 1.7 \%$, but the $\mathrm{rSO}_{2}$ level decreased to $29.4 \% \pm 2.5 \%$ in the ischemic state. The blood vessels of the intestinal tract that we wished to evaluate were ligated, and both sides of the intestinal tract were blocked with clamp forceps to inhibit mucosal blood flow. We were then able to accurately determine the TOS of the intestinal wall of several millimeters (figure not shown).

\section{Animal experiment}

Experiments were performed under a project license (No. 015-2019) granted by the institutional ethics board of the Foundation for Kobe International Medical Alliance, Kobe, Japan, in compliance with the institutional guidelines for the care and use of animals.

Specific pathogen-free porcine models (body weight $45 \pm 5 \mathrm{~kg}$; male) were used for this experiment $(\mathrm{n}=2)$. The pre-carry-in treatment was as follows: A mixture of ketamine $(10 \mathrm{mg} / \mathrm{kg} ; 500 \mathrm{mg}$ for intramuscular injection of Ketalal: Daiichi Sankyo Propharma Co., Ltd.) and xylazine ( $2 \mathrm{mg} / \mathrm{kg}$; Celactal 2\% injection: Bayer Medical Co., Ltd.) was administered intramuscularly, and atropine sulfate $(0.5 \mathrm{mg} / \mathrm{head}$; atropine sulfate injection $0.5 \mathrm{mg}$ "Tanabe", Mitsubishi Tanabe Pharma Corporation) was administered intravenously for sedation and prevention of casting and pulse elimination.

The porcine models were anesthetized with inhaled isoflurane (5\% concentration, 3\% oxygen flow; Escaine: Mylan Pharmaceutical Co., Ltd.) until the jaw muscles relaxed and tracheal intubation was possible. Thereafter, sevoflurane $(2-5 \%)$ was used for continued inhalation anesthesia, and an infusion of saline or extracellular fluid solution (Soldem 3A) was started. Intravenous rocuronium bromide $(0.6 \mathrm{~L} / \mathrm{kg})$ or vecuronium bromide (masculate; $0.1 \mathrm{mg} / \mathrm{kg}$ ) was administered as a muscle relaxant, and the models were attached to a ventilator.

\section{Evaluation of $\mathrm{rSO}_{2}$ at the bronchial stump during a right lower lobectomy}

Under general anesthesia, the right lung was collapsed by separate lung ventilation, followed by thoracoscopic surgery. Then, thoracoscopic surgery was performed as follows: The pulmonary artery, inferior pulmonary vein, and lower lobe bronchus were cut with a stapler (Powered Echelon $45 \mathrm{~mm}$, Ethicon Endosurgery, Johnson and Johnson, Tokyo, Japan), and the lower lobe was resected.

Firstly, the $\mathrm{rSO}_{2}$ level was measured at multiple points in the right bronchus: The $\mathrm{rSO}_{2}$ level of the main bronchus (MB), intermediate bronchial trunk (IT), and bronchial stump (BS) were measured after the right lower lobectomy (BS1), when the middle bronchus was clamped with forceps (BS2) and when the clamp was released (BS3) (Figure 3). The $\mathrm{rSO}_{2}$ level of the bronchial stump was measured on the site $5 \mathrm{~mm}$ of the central side of the stump. The micro-TOS sensor was applied to the target area, and measurements were obtained every second for 10 seconds once the value had stabilized. When all bronchial arteries were preserved, the $\mathrm{rSO}_{2}$ level of the bronchial wall was used as the positive control, and when all bronchial arteries were completely blocked, the $\mathrm{rSO}_{2}$ level of the bronchial wall was used as the negative control.

Secondly, the $\mathrm{rSO}_{2}$ level was measured at the fixed point of the bronchial stump. Multiple points of the bronchial arteries were then cut in stages as follows (Figure 4): Every bronchial artery was preserved before the lower lobe resection (i), the bronchial artery running from below to inside the trachea was ligated (ii), right lower lobe bronchotomy was performed (iii), a bronchial artery was ligated at the outside of the bronchi at the middle bronchial level (iv), and finally, a bronchial artery was ligated at the right main bronchial level (v).

\section{Statistical methods}

The Wilcoxon or Kruskal-Wallis test was used to determine any significant differences between the two unpaired groups. Analysis was performed using the $\mathrm{JMP}^{\circledR} 14.2$ 
A

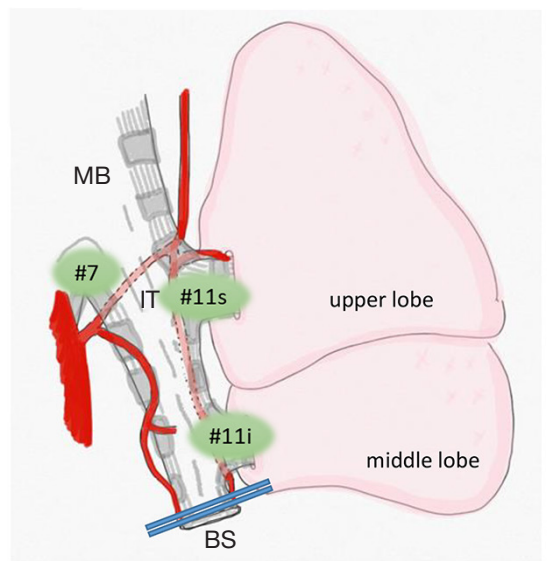

B

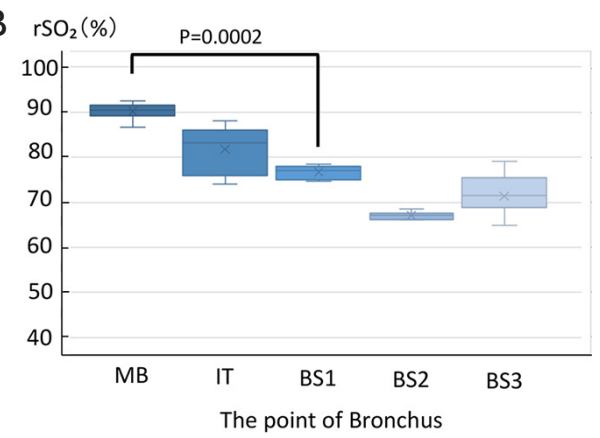

Figure 3 Evaluation of tissue oxygen saturation of the lower lobe bronchial stump during a right lower lobectomy. (A) Measurement site with schema. (B) $\mathrm{rSO}_{2}$ level at each measurement site. The $\mathrm{rSO}_{2}$ level was measured at each point on the bronchial wall. $\mathrm{MB}$, main bronchus; IT, intermedial bronchial trunk; BS1, bronchial stump; BS2, near the bronchial stump when clamping the middle bronchus with forceps; BS3, indication of the location of the BS2 clamp prior to its removal. The bronchial block at BS2 significantly reduced the $\mathrm{rSO}_{2}$ level; however, the $\mathrm{rSO}_{2}$ level increased after the blockade was released (BS3).

statistical analysis software (SAS Institute Inc., Cary, NC). The significance level was set at $\mathrm{P}<0.01$.

\section{Results}

The $\mathrm{rSO}_{2}$ level was measured at each point in the right bronchus (Figure 3), and the $\mathrm{rSO}_{2}$ level near the bronchial stump was semi-quantified. The $\mathrm{rSO}_{2}$ level of the preserved bronchial wall was $90.5 \% \pm 1.8 \%$ in the right main bronchus, which was defined as the upper limit positive control (Figure 3, $\mathrm{MB})$. In the preserved bronchial artery, the $\mathrm{rSO}_{2}$ level at every point was semi-quantified with the micro-TOS sensor. The
A

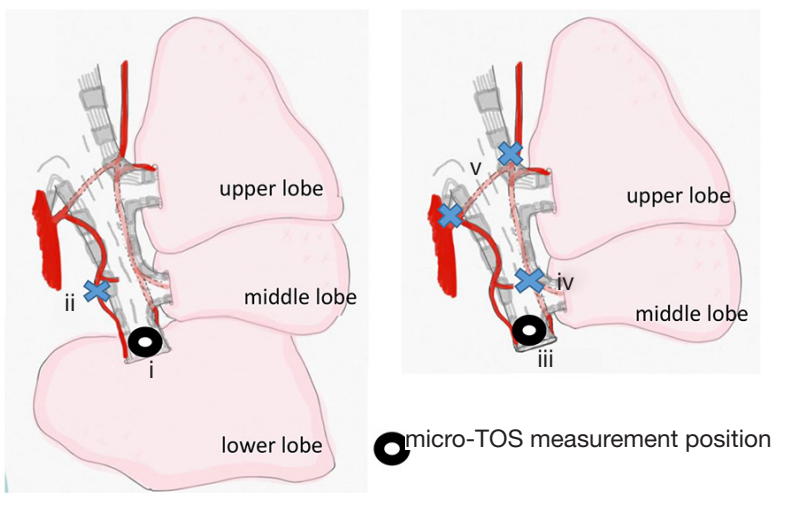

B

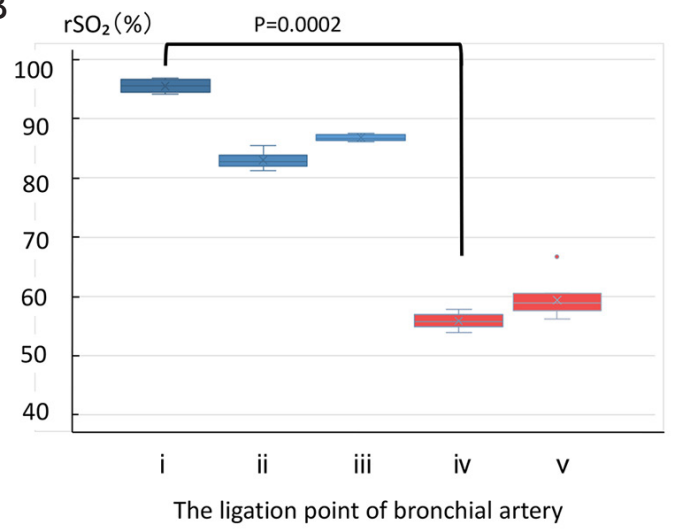

Figure 4 Relationship between the ligation site of the bronchial artery and the $\mathrm{rSO}_{2}$ level at the bronchial stump. (A) Cut level of the bronchial artery. (B) The $\mathrm{rSO}_{2}$ level at a fixed point in the bronchial stump. i: Bronchial artery preservation state before the lower lobe resection. ii: After ligation of the bronchial artery running from below to inside the trachea. iii: After lower lobe bronchotomy. iv: After ligation of the bronchial arteries that run outside of the bronchi at the middle bronchial level. v: After ligation of the bronchial arteries at the right main bronchial level. When the bronchial arteries were preserved, the $\mathrm{rSO}_{2}$ level remained above $80 \%$; however, when both the outer and inner bronchial arteries were ligated (iv), the $\mathrm{rSO}_{2}$ level decreased to $55.7 \% \pm 1.2 \%$.

$\mathrm{rSO}_{2}$ level at the central end of the middle bronchial trunk (near \#11, inter-lobar nodes) was $83.2 \% \pm 5.1 \%$ (Figure 3, IT), and the $\mathrm{rSO}_{2}$ level in the bronchial stump was $77.1 \% \pm 1.4 \%$ (Figure 3, BS1). The $\mathrm{rSO}_{2}$ level at the center of the bronchus was significantly higher than that of the bronchial stump $(\mathrm{P}=0.0002)$. When the bronchial stump was centrally clamped, the $\mathrm{rSO}_{2}$ level in the bronchial stump decreased to $67.1 \% \pm 0.8 \%$ (Figure 3, BS2). This value was defined as the negative control. When the clamp was 
released, the $\mathrm{rSO}_{2}$ level in the bronchial stump increased to $71.5 \% \pm 4.6 \%$ (Figure 3, BS3).

The $\mathrm{rSO}_{2}$ level was then evaluated at a fixed point in the bronchial stump when the bronchial artery was cut at different levels (Figure 4). When the bronchial artery was preserved, the $\mathrm{rSO}_{2}$ level was $95.5 \% \pm 1.0 \%$ (Figure 4 , i). The bronchi and bronchial arteries were then sequentially dissected from the periphery toward the center. First, the descending bronchial artery on the medial side of the bronchial bifurcation was cut, and the $\mathrm{rSO}_{2}$ level of the bronchial wall decreased slightly to $82.8 \% \pm 1.3 \%$ (Figure 4 , ii). Then, the bronchi were cut, and the $\mathrm{rSO}_{2}$ level remained at a similar level at $86.7 \% \pm 0.5 \%$ (Figure 4, iii). The descending bronchial artery on the outside of the middle bronchus was then cut, and the $\mathrm{rSO}_{2}$ level abruptly decreased to $55.7 \% \pm 1.2 \%$ (Figure 4, iv). Finally, the right bronchial artery was cut at the level of the right main bronchus, and the $\mathrm{rSO}_{2}$ level remained relatively constant at $58.9 \% \pm 2.9 \%$ (Figure 4, v).

\section{Discussion}

To the best of our knowledge, this study is the first to semi-quantitatively measure blood flow at the bronchial stump during the transection of the bronchial artery. The bronchial arteries of the right lower lobe are distributed from the lateral side (middle bronchial trunk or outside) and medial side (tracheal bifurcation or inside). The $\mathrm{rSO}_{2}$ level significantly reduced to $<60 \%(\mathrm{P}=0.0002)$ when the bronchial artery branch, running at the high level on the lateral side of the bronchus, and the bronchial artery branch, running on the medial side, were severed.

A previous study examined extracorporeal circulation in the brain region in a cardiovascular surgery setting and showed that postoperative brain injury, such as cerebral infarction and intellectual impairment, occurred if the $\mathrm{rSO}_{2}$ level measured with a forehead probe dropped to $\leq 55-60 \%$ for longer than $5 \mathrm{~min}$ or decreased to an initial range of $76-86 \%(19,20)$.

The lower limit of the TOS required to prevent hypoxic tissue damage in the bronchus is currently unknown; however, with reference to other tissues, the TOS of bronchial tissues may need to be kept $>60 \%$. In this study, the central transection of the bronchial artery reduced the $\mathrm{rSO}_{2}$ level to $<60 \%$, indicating that cutting the bronchial artery at the central level may increase the risk of suture failure at the bronchial stump.

A BPF does not always occur when the bronchial artery is completely cut because blood flow to the bronchi is supplied from the bronchial artery and pulmonary circulation (8). For example, in lung transplantation, the bronchial artery is not anastomosed; however, the donor lung is still able to successfully engraft in the recipient.

In this study, we demonstrated that maintaining the blood flow of the bronchial artery into the middle lobe kept the $\mathrm{rSO}_{2}$ of the bronchial stump at an adequate level. Blood possibly flows into the lower lobe bronchus through the capillaries of the bronchial mucosa and submucosa between the middle and lower lobe bronchi. Individual differences can be observed in the degree of development of the bronchial arteries that flow into the remaining right middle lobe and the quality of oxygenation of the pulmonary circulation system in the right lung. Therefore, there may be differences in the amount of oxygen supplied to the lower lobe bronchial stump via the mucosa and submucosa. In this study, when at least one of the two inner or outer bronchial arteries were preserved, the TOS at the bronchial stump was maintained with an $\mathrm{rSO}_{2}$ level of $\geq 80 \%$. When both arteries were cut, the $\mathrm{rSO}_{2}$ level dropped to $<60 \%$, and the risk of developing a bronchial stump fistula may have increased.

In clinical cases, additional reinforcement, such as covering the bronchial stump with a pericardial fat-tissue flap or intercostal muscle flap (21-23), may be considered to further reduce the risk of a bronchofistula. However, it is unclear whether strengthening the anastomotic site by covering it with other tissues may prevent suture failure.

\section{Limitations}

To adhere to the bioethical considerations for large animals, this pilot study used a minimum number of animals. In addition, pigs were chosen as our animal model because their physical size is closest to humans; however, the microTOS system has yet to be validated for use in human lobectomies in clinical studies.

\section{Conclusions}

The relationship between the surgical ligation level of the bronchial artery and the desaturation of the bronchial stump during a lobectomy was clarified in this porcine model study. During hilar lymph node dissection around the bronchus in the right lower lobe, central ligation of the bronchial artery may cause severe hypoxia at the bronchial stump. By preserving either the inside or outside of the bronchial artery running through the bronchial wall to the 
periphery, TOS at the bronchial stump may be maintained above the level at which hypoxia occurs.

\section{Acknowledgments}

We appreciated Fujita Medical Instruments Co., Ltd. (Tokyo, Japan) for kindly providing the TOS system for this research. We would like to especially thank Mr. Haruo Yamamura (TOSTEC Co., Ltd., Tokyo, Japan) for the development of the rod-shaped micro-TOS sensor. We would also like to thank Ms. Ami Yamanaka for her assistance in animal experiments. We thank Mr. Satoshi Haneda, Olympus Medical (Tokyo, Japan), for his technical assistance in handling the optical instruments. In addition, we thank Ms. Satoko Kimura and Mr. Toshiaki Ishibashi, MeDIP: Medical Device Innovation Platform, Foundation for Kobe International Medical Alliance (Hyogo, Japan), for providing the instruments necessary for the animal experiments.

Funding: The institutional research support grant of Kochi Medical School Hospital (Incentive grant \#51010643), 2019.

\section{Footnote}

Conflicts of Interest: All authors have completed the ICMJE uniform disclosure form (available at http://dx.doi. org/10.21037/qims-20-1057). The authors have no conflicts of interest to declare.

Ethical Statement: Experiments were performed under a project license (No. 015-2019) granted by the institutional ethics board of the Foundation for Kobe International Medical Alliance, Kobe, Japan, in compliance with the institutional guidelines for the care and use of animals.

Open Access Statement: This is an Open Access article distributed in accordance with the Creative Commons Attribution-NonCommercial-NoDerivs 4.0 International License (CC BY-NC-ND 4.0), which permits the noncommercial replication and distribution of the article with the strict proviso that no changes or edits are made and the original work is properly cited (including links to both the formal publication through the relevant DOI and the license). See: https://creativecommons.org/licenses/by-nc-nd/4.0/.

\section{References}

1. Buchs NC, Gervaz P, Secic M, Bucher P, Mugnier-
Konrad B, Morel P. Incidence, consequences, and risk factors for anastomotic dehiscence after colorectal surgery: a prospective monocentric study. Int J Colorectal Dis 2008;23:265-270.

2. Allen MS, Darling GE, Pechet TTV, Mitchell JD, Herndon JE 2nd, Landreneau RJ, Inculet RI, Jones DR, Meyers BF, Harpole DH, Putnam JB Jr, Rusch VW, ACOSOG Z0030 Study Group. Morbidity and mortality of major pulmonary resections in patients with early-stage lung cancer: initial results of the randomized, prospective ACOSOG Z0030 trial. Ann Thorac Surg 2006;81:10131019; discussion 1019-1020.

3. Cerfolio RJ. The incidence, etiology, and prevention of postresectional bronchopleural fistula. Semin Thorac Cardiovasc Surg 2001;13:3-7.

4. Sirbu H, Busch T, Aleksic I, Schreiner W, Oster O, Dalichau H. Bronchopleural fistula in the surgery of non-small cell lung cancer: incidence, risk factors, and management. Ann Thorac Cardiovasc Surg 2001;7:330-6.

5. Asamura H, Naruke T, Tsuchiya R, Goya T, Kondo H, SuemasuK. Bronchopleural fistulas associated with lung cancer operations: univariate and multivariate analysis of risk factors, management, and outcome. J Thorac Cardiovasc Surg 1992;104:1456-64.

6. Vester SR, Faber LP, Kittle CF, Warren WH, Jensik RJ. Bronchopleural fistula after stapled closure of bronchus. Ann Thorac Surg 1991;52:1253-1257; discussion 1257-1258.

7. Cauldwell EW, Siekert RG. The bronchial arteries; an anatomic study of 150 human cadavers. Surg Gynecol Obstet 1948;86:395-412.

8. Barman SA, Ardell JL, Parker JC, Perry ML, Taylor AE. Pulmonary and systemic blood flow contributions to upper airways in canine lung. Am J Physiol 1988;255:H1130-5.

9. Nathan H, Orda R, Barkay M. The right bronchial artery. Anatomical considerations and surgical approach. Thorax 1970;25:328-333.

10. Salassa JR, Pearson BW, Payne WS. Gross and microscopical blood supply of the trachea. Ann Thorac Surg 1977;24:100-7.

11. Ginsberg RJ, Rubinstein LV. Randomized trial of lobectomy versus limited resection for T1 N0 nonsmall cell lung cancer. Ann Thorac Surg 1995;60:615-22; discussion 622-3.

12. Novotny HR, Alvis D. A method of photographing fluorescence in circulating blood of the human eye. Tech Doc Rep SAMTDR USAF Sch Aerosp Med 1960;60$82: 1-4$ 
13. Mitsuhashi N, Kimura F, Shimizu H, Imamaki M, Yoshidome H, Ohtsuka M, Kato A, Yoshitomi H, Nozawa S, Furukawa K, Takeuchi D, Takayashiki T, Suda K, Igarashi T, Miyazaki M. Usefulness of intraoperative fluorescence imaging to evaluate local anatomy in hepatobiliary surgery. J Hepatobiliary Pancreat Surg 2008; $15: 508-514$.

14. Takahashi M, Ishikawa T, Higashidani K, Katoh H. SPY: an innovative intra-operative imaging system to evaluate graft patency during off-pump coronary artery bypass grafting. Interact Cardiovasc Thorac Surg 2004;3:479-483.

15. Suzuki A, Fujiwara M, Mizukami T, Fukamizu H. Delayed distally-based super sural flap: evaluation by indocyanine green fluorescence angiography. J Plast Reconstr Aesthet Surg 2008;61:467-9.

16. Yano A, Orihashi D, Yoshida Y, Kuriyama M. Nearinfrared spectroscopy for monitoring free jejunal flap. J Plast Reconstr Aesthet Surg 2021;74:108-115.

17. Kim MB, Ward DS, Cartwright CR, Kolano J, Chlebowski $\mathrm{S}$, Henson LC. Estimation of jugular venous O2 saturation from cerebral oximetry or arterial $\mathrm{O} 2$ saturation during isocapnic hypoxia. J Clin Monit Comput 2000;16:191-9.

18. Hongo K, Kobayashi S, Okudera H, Hokama M, Nakagawa F. Noninvasive cerebral optical spectroscopy:

Cite this article as: Yamamoto $M$, Anayama T, Okada $H$, Miyazaki R, Orihashi K. Surgical ligation level of the bronchial artery influences tissue oxygen saturation of the bronchus and the incidence of postoperative bronchofistula after pulmonary lobectomy. Quant Imaging Med Surg 2021;11(7):3157-3164. doi: 10.21037/qims-20-1057 depth-resolved measurements of cerebral haemodynamics using indocyanine green. Neurol Res 1995;17:89-93.

19. Orihashi K, Sueda T, Okada K, Imai K. Near-infrared spectroscopy for monitoring cerebral ischemia during selective cerebral perfusion. Eur J Cardiothorac Surg 2004;26:907-911.

20. Olsson C, Thelin S. Regional cerebral saturation monitoring with near-infrared spectroscopy during selective antegrade cerebral perfusion: diagnostic performance and relationship to postoperative stroke. J Thorac Cardiovasc Surg 2006;131:371-9.

21. Llewellyn-Bennett R, Wotton R, West D. Prophylactic flap coverage and the incidence of bronchopleural fistulae after pneumonectomy. Interact Cardiovasc Thorac Surg 2013;16:681-5.

22. Di Maio M, Perrone F, Deschamps C, Rocco G. A metaanalysis of the impact of bronchial stump coverage on the risk of bronchopleural fistula after pneumonectomy. Eur J Cardiothorac Surg 2015;48:196-200.

23. Taghavi S, Marta GM, Lang G, Seebacher G, Winkler G, Schmid K, Klepetko W. Bronchial stump coverage with a pedicled pericardial flap: an effective method for prevention of postpneumonectomy bronchopleural fistula. Ann Thorac Surg 2005;79:284-8. 